\title{
TERAPI KOMPLEMENTER DALAM KEPERAWATAN
}

\author{
Widyatuti *
}

\begin{abstract}
Abstrak
Terapi komplementer akhir-akhir ini menjadi isu di banyak negara. Masyarakat menggunakan terapi ini dengan alasan keyakinan, keuangan, reaksi obat kimia dan tingkat kesembuhan. Perawat mempunyai peluang terlibat dalam terapi ini, tetapi memerlukan dukungan hasil-hasil penelitian (evidence-based practice). Pada dasarnya terapi komplementer telah didukung berbagai teori, seperti teori Nightingale, Roger, Leininger, dan teori lainnya. Terapi komplementer dapat digunakan di berbagai level pencegahan. Perawat dapat berperan sesuai kebutuhan klien.
\end{abstract}

Kata kunci: keperawatan, terapi alternatif, terapi komplementer

\begin{abstract}
Complementary therapy has emerged as a common health issue in the countries worldwide. People choose the complementary therapy based on many reasons such as belief, financial, avoiding the chemical reaction from medicine, and positive healing outcome. Nurse has great opportunity to deliver and develop complementary therapy supported by scientific evidences. Basically, the complementary therapy theoretical justification has been established by several nursing theory, as the Nightingale's, Roger's, Leininger's and many others. Complementary therapy can be delivered in various prevention level. In accordance to the purpose, nurse should perform his/her role based on particular client's needs.
\end{abstract}

Key words: alternative therapy, complementary therapy, nursing

\section{PENDAHULUAN}

Perkembangan terapi komplementer akhirakhir ini menjadi sorotan banyak negara. Pengobatan komplementer atau alternatif menjadi bagian penting dalam pelayanan kesehatan di Amerika Serikat dan negara lainnya (Snyder \& Lindquis, 2002). Estimasi di Amerika Serikat 627 juta orang adalah pengguna terapi alternatif dan 386 juta orang yang mengunjungi praktik konvensional (Smith et al., 2004). Data lain menyebutkan terjadi peningkatan jumlah pengguna terapi komplementer di Amerika dari 33\% pada tahun 1991 menjadi 42\% di tahun 1997 (Eisenberg, 1998 dalam Snyder \& Lindquis, 2002).

Klien yang menggunakan terapi komplemeter memiliki beberapa alasan. Salah satu alasannya adalah filosofi holistik pada terapi komplementer, yaitu adanya harmoni dalam diri dan promosi kesehatan dalam terapi komplementer. Alasan lainnya karena klien ingin terlibat untuk pengambilan keputusan dalam pengobatan dan peningkatan kualitas hidup dibandingkan sebelumnya. Sejumlah $82 \%$ klien melaporkan adanya reaksi efek samping dari pengobatan konvensional yang diterima menyebabkan memilih terapi komplementer (Snyder \& Lindquis, 2002).

Terapi komplementer yang ada menjadi salah satu pilihan pengobatan masyarakat. Di berbagai tempat pelayanan kesehatan tidak sedikit klien bertanya tentang terapi komplementer atau alternatif pada petugas kesehatan seperti dokter ataupun perawat. Masyarakat mengajak dialog perawat untuk penggunaan terapi alternatif (Smith et al., 2004). Hal ini terjadi karena klien ingin mendapatkan pelayanan yang sesuai dengan pilihannya, sehingga apabila keinginan terpenuhi akan berdampak ada kepuasan klien. Hal ini dapat menjadi peluang bagi perawat untuk berperan memberikan terapi komplementer. 
Peran yang dapat diberikan perawat dalam terapi komplementer atau alternatif dapat disesuaikan dengan peran perawat yang ada, sesuai dengan batas kemampuannya. Pada dasarnya, perkembangan perawat yang memerhatikan hal ini sudah ada. Sebagai contoh yaitu American Holistic Nursing Association (AHNA), Nurse Healer Profesional Associates (NHPA) (Hitchcock et al., 1999). Ada pula National Center for Complementary/Alternative Medicine (NCCAM) yang berdiri tahun 1998 (Snyder \& Lindquis, 2002).

Kebutuhan masyarakat yang meningkat dan berkembangnya penelitian terhadap terapi komplementer menjadi peluang perawat untuk berpartisipasi sesuai kebutuhan masyarakat. Perawat dapat berperan sebagai konsultan untuk klien dalam memilih alternatif yang sesuai ataupun membantu memberikan terapi langsung. Namun, hal ini perlu dikembangkan lebih lanjut melalui penelitian (evidence-based practice) agar dapat dimanfaatkan sebagai terapi keperawatan yang lebih baik.

\section{TERAPI KOMPLEMENTER}

Terapi komplementer dikenal dengan terapi tradisional yang digabungkan dalam pengobatan modern. Komplementer adalah penggunaan terapi tradisional ke dalam pengobatan modern (Andrews et al., 1999). Terminologi ini dikenal sebagai terapi modalitas atau aktivitas yang menambahkan pendekatan ortodoks dalam pelayanan kesehatan (Crips \& Taylor, 2001). Terapi komplementer juga ada yang menyebutnya dengan pengobatan holistik. Pendapat ini didasari oleh bentuk terapi yang mempengaruhi individu secara menyeluruh yaitu sebuah keharmonisan individu untuk mengintegrasikan pikiran, badan, dan jiwa dalam kesatuan fungsi (Smith et al., 2004).

Pendapat lain menyebutkan terapi komplementer dan alternatif sebagai sebuah domain luas dalam sumber daya pengobatan yang meliputi sistem kesehatan, modalitas, praktik dan ditandai dengan teori dan keyakinan, dengan cara berbeda dari sistem pelayanan kesehatan yang umum di masyarakat atau budaya yang ada (Complementary and alternative medicine/CAM Research Methodology Conference, 1997 dalam Snyder \& Lindquis, 2002). Terapi komplementer dan alternatif termasuk didalamnya seluruh praktik dan ide yang didefinisikan oleh pengguna sebagai pencegahan atau pengobatan penyakit atau promosi kesehatan dan kesejahteraan.

Definisi tersebut menunjukkan terapi komplemeter sebagai pengembangan terapi tradisional dan ada yang diintegrasikan dengan terapi modern yang mempengaruhi keharmonisan individu dari aspek biologis, psikologis, dan spiritual. Hasil terapi yang telah terintegrasi tersebut ada yang telah lulus uji klinis sehingga sudah disamakan dengan obat modern. Kondisi ini sesuai dengan prinsip keperawatan yang memandang manusia sebagai makhluk yang holistik (bio, psiko, sosial, dan spiritual).

Prinsip holistik pada keperawatan ini perlu didukung kemampuan perawat dalam menguasai berbagai bentuk terapi keperawatan termasuk terapi komplementer. Penerapan terapi komplementer pada keperawatan perlu mengacu kembali pada teori-teori yang mendasari praktik keperawatan. Misalnya teori Rogers yang memandang manusia sebagai sistem terbuka, kompleks, mempunyai berbagai dimensi dan energi. Teori ini dapat mengembangkan pengobatan tradisional yang menggunakan energi misalnya tai chi, chikung, dan reiki.

Teori keperawatan yang ada dapat dijadikan dasar bagi perawat dalam mengembangkan terapi komplementer misalnya teori transkultural yang dalam praktiknya mengaitkan ilmu fisiologi, anatomi, patofisiologi, dan lain-lain. Hal ini didukung dalam catatan keperawatan Florence Nightingale yang telah menekankan pentingnya mengembangkan lingkungan untuk penyembuhan dan pentingnya terapi seperti musik dalam proses penyembuhan. Selain itu, terapi komplementer meningkatkan kesempatan perawat dalam menunjukkan caring pada klien (Snyder \& Lindquis, 2002). 
Hasil penelitian terapi komplementer yang dilakukan belum banyak dan tidak dijelaskan dilakukan oleh perawat atau bukan. Beberapa yang berhasil dibuktikan secara ilmiah misalnya terapi sentuhan untuk meningkatkan relaksasi, menurunkan nyeri, mengurangi kecemasan, mempercepat penyembuhan luka, dan memberi kontribusi positif pada perubahan psikoimunologik (Hitchcock et al., 1999). Terapi pijat (massage) pada bayi yang lahir kurang bulan dapat meningkatkan berat badan, memperpendek hari rawat, dan meningkatkan respons. Sedangkan terapi pijat pada anak autis meningkatkan perhatian dan belajar. Terapi pijat juga dapat meningkatkan pola makan, meningkatkan citra tubuh, dan menurunkan kecemasan pada anak susah makan (Stanhope, 2004). Terapi kiropraksi terbukti dapat menurunkan nyeri haid dan level plasma prostaglandin selama haid (Fontaine, 2005).

Hasil lainnya yang dilaporkan misalnya penggunaan aromaterapi. Salah satu aromaterapi berupa penggunaan minyak esensial berkhasiat untuk mengatasi infeksi bakteri dan jamur (Buckle, 2003). Minyak lemon thyme mampu membunuh bakteri streptokokus, stafilokokus dan tuberkulosis (Smith et al., 2004). Tanaman lavender dapat mengontrol minyak kulit, sedangkan teh dapat membersihkan jerawat dan membatasi kekambuhan (Key, 2008). Dr. Carl menemukan bahwa penderita kanker lebih cepat sembuh dan berkurang rasa nyerinya dengan meditasi dan imagery (Smith et al., 2004). Hasil riset juga menunjukkan hipnoterapi meningkatkan suplai oksigen, perubahan vaskular dan termal, mempengaruhi aktivitas gastrointestinal, dan mengurangi kecemasan (Fontaine, 2005).

Hasil-hasil tersebut menyatakan terapi komplementer sebagai suatu paradigma baru (Smith et al., 2004). Bentuk terapi yang digunakan dalam terapi komplementer ini beragam sehingga disebut juga dengan terapi holistik. Terminologi kesehatan holistik mengacu pada integrasi secara menyeluruh dan mempengaruhi kesehatan, perilaku positif, memiliki tujuan hidup, dan pengembangan spiritual (Hitchcock et al., 1999).
Terapi komplementer dengan demikian dapat diterapkan dalam berbagai level pencegahan penyakit.

Terapi komplementer dapat berupa promosi kesehatan, pencegahan penyakit ataupun rehabilitasi. Bentuk promosi kesehatan misalnya memperbaiki gaya hidup dengan menggunakan terapi nutrisi. Seseorang yang menerapkan nutrisi sehat, seimbang, mengandung berbagai unsur akan meningkatkan kesehatan tubuh. Intervensi komplementer ini berkembang di tingkat pencegahan primer, sekunder, tersier dan dapat dilakukan di tingkat individu maupun kelompok misalnya untuk strategi stimulasi imajinatif dan kreatif (Hitchcock et al., 1999).

Pengobatan dengan menggunakan terapi komplementer mempunyai manfaat selain dapat meningkatkan kesehatan secara lebih menyeluruh juga lebih murah. Terapi komplementer terutama akan dirasakan lebih murah bila klien dengan penyakit kronis yang harus rutin mengeluarkan dana. Pengalaman klien yang awalnya menggunakan terapi modern menunjukkan bahwa biaya membeli obat berkurang 200-300 dolar dalam beberapa bulan setelah menggunakan terapi komplementer (Nezabudkin, 2007).

Minat masyarakat Indonesia terhadap terapi komplementer ataupun yang masih tradisional mulai meningkat. Hal ini dapat dilihat dari banyaknya pengunjung praktik terapi komplementer dan tradisional di berbagai tempat. Selain itu, sekolah-sekolah khusus ataupun kursuskursus terapi semakin banyak dibuka. Ini dapat dibandingkan dengan Cina yang telah memasukkan terapi tradisional Cina atau traditional Chinese Medicine (TCM) ke dalam perguruan tinggi di negara tersebut (Snyder \& Lindquis, 2002).

Kebutuhan perawat dalam meningkatnya kemampuan perawat untuk praktik keperawatan juga semakin meningkat. Hal ini didasari dari berkembangnya kesempatan praktik mandiri. Apabila perawat mempunyai kemampuan yang dapat dipertanggungjawabkan akan meningkatkan hasil yang lebih baik dalam pelayanan keperawatan. 


\section{MACAM TERAPI KOMPLEMENTER}

Terapi komplementer ada yang invasif dan noninvasif. Contoh terapi komplementer invasif adalah akupuntur dan cupping (bekam basah) yang menggunakan jarum dalam pengobatannya. Sedangkan jenis non-invasif seperti terapi energi (reiki, chikung, tai chi, prana, terapi suara), terapi biologis (herbal, terapi nutrisi, food combining, terapi jus, terapi urin, hidroterapi colon dan terapi sentuhan modalitas; akupresur, pijat bayi, refleksi, reiki, rolfing, dan terapi lainnya (Hitchcock et al., 1999)

National Center for Complementary/ Alternative Medicine (NCCAM) membuat klasifikasi dari berbagai terapi dan sistem pelayanan dalam lima kategori. Kategori pertama, mind-body therapy yaitu memberikan intervensi dengan berbagai teknik untuk memfasilitasi kapasitas berpikir yang mempengaruhi gejala fisik dan fungsi tubuh misalnya perumpamaan (imagery), yoga, terapi musik, berdoa, journaling, biofeedback, humor, tai chi, dan terapi seni.

Kategori kedua, Alternatif sistem pelayanan yaitu sistem pelayanan kesehatan yang mengembangkan pendekatan pelayanan biomedis berbeda dari Barat misalnya pengobatan tradisional Cina, Ayurvedia, pengobatan asli Amerika, cundarismo, homeopathy, naturopathy. Kategori ketiga dari klasifikasi NCCAM adalah terapi biologis, yaitu natural dan praktik biologis dan hasil-hasilnya misalnya herbal, makanan).

Kategori keempat adalah terapi manipulatif dan sistem tubuh. Terapi ini didasari oleh manipulasi dan pergerakan tubuh misalnya pengobatan kiropraksi, macam-macam pijat, rolfing, terapi cahaya dan warna, serta hidroterapi. Terakhir, terapi energi yaitu terapi yang fokusnya berasal dari energi dalam tubuh (biofields) atau mendatangkan energi dari luar tubuh misalnya terapetik sentuhan, pengobatan sentuhan, reiki, external qi gong, magnet. Klasifikasi kategori kelima ini biasanya dijadikan satu kategori berupa kombinasi antara biofield dan bioelektromagnetik (Snyder \& Lindquis, 2002).
Klasifikasi lain menurut Smith et al (2004) meliputi gaya hidup (pengobatan holistik, nutrisi), botanikal (homeopati, herbal, aromaterapi); manipulatif (kiropraktik, akupresur \& akupunktur, refleksi, massage); mind-body (meditasi, guided imagery, biofeedback, color healing, hipnoterapi). Jenis terapi komplementer yang diberikan sesuai dengan indikasi yang dibutuhkan. Contohnya pada terapi sentuhan memiliki beberapa indikasinya seperti meningkatkan relaksasi, mengubah persepsi nyeri, menurunkan kecemasan, mempercepat penyembuhan, dan meningkatkan kenyamanan dalam proses kematian (Hitchcock et al., 1999).

Jenis terapi komplementer banyak sehingga seorang perawat perlu mengetahui pentingnya terapi komplementer. Perawat perlu mengetahui terapi komplementer diantaranya untuk membantu mengkaji riwayat kesehatan dan kondisi klien, menjawab pertanyaan dasar tentang terapi komplementer dan merujuk klien untuk mendapatkan informasi yang reliabel, memberi rujukan terapis yang kompeten, ataupun memberi sejumlah terapi komplementer (Snyder \& Lindquis, 2002). Selain itu, perawat juga harus membuka diri untuk perubahan dalam mencapai tujuan perawatan integratif (Fontaine, 2005).

\section{PERAN PERAWAT}

Peran perawat yang dapat dilakukan dari pengetahuan tentang terapi komplementer diantaranya sebagai konselor, pendidik kesehatan, peneliti, pemberi pelayanan langsung, koordinator dan sebagai advokat. Sebagai konselor perawat dapat menjadi tempat bertanya, konsultasi, dan diskusi apabila klien membutuhkan informasi ataupun sebelum mengambil keputusan. Sebagai pendidik kesehatan, perawat dapat menjadi pendidik bagi perawat di sekolah tinggi keperawatan seperti yang berkembang di Australia dengan lebih dahulu mengembangkan kurikulum pendidikan (Crips \& Taylor, 2001). Peran perawat sebagai peneliti di antaranya dengan melakukan berbagai penelitian yang dikembangkan dari hasilhasil evidence-based practice. 
Perawat dapat berperan sebagai pemberi pelayanan langsung misalnya dalam praktik pelayanan kesehatan yang melakukan integrasi terapi komplementer (Snyder \& Lindquis, 2002). Perawat lebih banyak berinteraksi dengan klien sehingga peran koordinator dalam terapi komplementer juga sangat penting. Perawat dapat mendiskusikan terapi komplementer dengan dokter yang merawat dan unit manajer terkait. Sedangkan sebagai advokat perawat berperan untuk memenuhi permintaan kebutuhan perawatan komplementer yang mungkin diberikan termasuk perawatan alternatif (Smith et al.,2004).

\section{PENUTUP}

Masyarakat Indonesia sudah mengenal adanya terapi tradisional seperti jamu yang telah berkembang lama. Kenyataannya klien yang berobat di berbagai jenjang pelayanan kesehatan tidak hanya menggunakan pengobatan Barat (obat kimia) tetapi secara mandiri memadukan terapi tersebut yang dikenal dengan terapi komplementer.

Perkembangan terapi komplementer atau alternatif sudah luas, termasuk didalamnya orang yang terlibat dalam memberi pengobatan karena banyaknya profesional kesehatan dan terapis selain dokter umum yang terlibat dalam terapi komplementer. Hal ini dapat meningkatkan perkembangan ilmu pengetahuan melalui penelitian-penelitian yang dapat memfasilitasi terapi komplementer agar menjadi lebih dapat dipertanggungjawabkan.

Perawat sebagai salah satu profesional kesehatan, dapat turut serta berpartisipasi dalam terapi komplementer. Peran yang dijalankan sesuai dengan peran-peran yang ada. Arah perkembangan kebutuhan masyarakat dan keilmuan mendukung untuk meningkatkan peran perawat dalam terapi komplementer karena pada kenyataannya, beberapa terapi keperawatan yang berkembang diawali dari alternatif atau tradisional terapi.

Kenyataan yang ada, buku-buku keperawatan membahas terapi komplementer sebagai isu praktik keperawatan abad ke 21. Isu ini dibahas dari aspek pengembangan kebijakan, praktik keperawatan, pendidikan, dan riset. Apabila isu ini berkembang dan terlaksana terutama oleh perawat yang mempunyai pengetahuan dan kemampuan tentang terapi komplementer, diharapkan akan dapat meningkatkan pelayanan kesehatan sehingga kepuasan klien dan perawat secara bersama-sama dapat meningkat $(\mathrm{HH}, \mathrm{TH})$.

* Staf Akademik Keperawatan Komunitas FIK UI

\section{KEPUSTAKAAN}

Andrews, M., Angone, K.M., Cray, J.V., Lewis, J.A., \& Johnson, P.H. (1999). Nurse's handbook of alternative and complementary therapies. Pennsylvania: Springhouse.

Buckle, S. (2003). Aromatherapy. http// .www.naturalhealthweb.com/articles, diperoleh 25 Januari 2008.

Fontaine, K.L. (2005). Complementary \& alternative therapies for nursing practice. 2 th ed. New Jersey: Pearson Prentice Hall.

Hitchcock, J.E, Schubert, P.E., Thomas, S.A. (1999). Community health nursing: Caring in action. USA: Delmar Publisher.

Key, G. (2008). Aromatherapy beauty tips. http// .www.naturalhealthweb. com/articles/ georgekey3.html, diperoleh 25 Januari 2008.

Nezabudkin, V. (2007). How to research alternatif treatment before using them.http// .www.naturalhealthweb.com/articles/ Nezabudkin1.html, diperoleh 25 Januari 2008.

Smith, S.F., Duell, D.J., Martin, B.C. (2004). Clinical nursing skills: Basic to advanced skills. New Jersey: Pearson Prentice Hall.

Snyder, M. \& Lindquist, R. (2002). Complementary/alternative therapies in nursing. 4th ed. New York: Springer.

Stanhope, M. \& Lancaster, J. (2004). Community $\&$ public health nursing. 6th ed. St. Louis: Mosby Inc. 